\title{
A replicable, low-burden mechanism for observing, recording and analysing mother- child interaction in population research
}

Short title: Mother-child interactions in population research

Authors: Penny Levickis, $\mathrm{PhD}^{1,2}$, Sheena Reilly, $\mathrm{PhD}^{2,3,4}$, Luigi Girolametto, $\mathrm{PhD}^{5}$, Obioha C Ukoumunne, $\mathrm{PhD}^{6}$, Melissa Wake, $\mathrm{MD}^{2,4,7}$

Institutions: $\quad{ }^{1}$ Newcastle University, Newcastle upon Tyne, UK

${ }^{2}$ Murdoch Childrens Research Institute, Parkville, Australia

${ }^{3}$ Menzies Health Institute Queensland, QLD, Australia

${ }^{4}$ University of Melbourne, Melbourne, Australia

${ }^{5}$ Department of Speech-Language Pathology, University of Toronto, Toronto, Canada

${ }^{6}$ NIHR CLAHRC South West Peninsula (PenCLAHRC), University of Exeter Medical School, Exeter, UK

${ }^{7}$ Department of Paediatrics and the Liggins Institute, The University of Auckland, Auckland, New Zealand

Correspondence to: Dr Penny Levickis

Newcastle University

School of Education, Communication \& Language Sciences

Queen Victoria Rd, Newcastle upon Tyne, NE1 7RU

$\mathrm{Ph}+44$ (0) $1912085120 \quad$ Email penny.levickis@ newcastle.ac.uk

This is the author manuscript accepted for publication and has undergone full peer review but has not been through the copyediting, typesetting, pagination and proofreading process, which may lead to differences between this version and the Version of Record. Please cite this article as doi: $10.1111 /$ cch.12615

This article is protected by copyright. All rights reserved. 
$\begin{array}{ll}\text { Word Count: } & \mathbf{3 , 0 9 1} \\ \text { Keywords: } & \text { mother-child interaction, language disorder, observational methods, } \\ & \text { reliability, child development }\end{array}$

\section{Additional Author Details:}

Penny Levickis $\mathrm{PhD}$

Newcastle University

School of Education, Communication \& Language Sciences

Queen Victoria Rd, Newcastle upon Tyne, NE1 7RU

$\mathrm{Ph}+44(0) 1912085120$

Email penny.levickis@newcastle.ac.uk

Sheena Reilly $\mathrm{PhD}$

Pro Vice Chancellor (Health)

Gold Coast Campus

Griffith University

QLD, Australia

T: +61 756780711

Emails.reilly@griffith.edu.au

Luigi Girolametto $\mathrm{PhD}$

Professor, c

T: +4169465456

Email 1.girolametto@utoronto.ca

Obioha C Ukoumunne $\mathrm{PhD}$

This article is protected by copyright. All rights reserved. 
Associate Professor, Medical Statistics

South Cloisters

University of Exeter, St Luke's Campus

Heavitree Rd

Exeter, UK EX1 2LU

T: +44 (0) 1392726070

Email O.C.Ukoumunne@ exeter.ac.uk

\author{
Melissa Wake MD \\ Centre for Community Child Health, Murdoch Childrens Research Institute \\ Flemington Road, \\ Parkville, VIC 3052, Australia \\ T: +6139345 5937 \\ Email melissa.wake@mcri.edu.au
}

\title{
ACKNOWLEDGEMENTS
}

The Let's Learn Language trial was funded by the Australian National Health and Medical Research Council (NHMRC) Strategic Award 384491. The authors thank the Let's Learn Language study team and all participating families, as well as Carly Vaness who carried out the inter-rater reliability for the current study. Dr Levickis was supported by the European Union's Horizon 2020 research and innovation programme under the Marie Sklodowska-Curie grant agreement No. 705044.The authors acknowledge the support of the NHMRC-funded Centre of Research Excellence in Child Language (\#1023493): Prof Wake (Senior Research Fellowship 1046518) and Prof Reilly (Practitioner Fellowship 1041892). Obi Ukoumunne was supported by the National Institute for Health Research (NIHR) Collaboration for Leadership in Applied Health Research and Care South West Peninsula (NIHR CLAHRC South West Peninsula). The views expressed are those of the authors and not necessarily those of the NHS, the NIHR or the Department of Health and Social Care. Research at the Murdoch Childrens Research Institute is supported by the Victorian 
Government's Operational Infrastructure Support Program. The researchers were independent of the funders.

Declaration of interest: The authors report no conflicts of interest. The authors are responsible for the content and writing of the paper.

\begin{abstract}
Background: There is growing evidence that specific styles of parent-child interaction benefit child development, particularly child language development. Direct observational techniques help clarify the behaviours and styles within parent-child interactions that may influence child language outcomes however, these techniques tend to be labour-intensive and costly. We report on the development of a replicable, low-burden mechanism for observing and coding specific maternal linguistic behaviours in a population-based cohort of 2-yearolds.

Methods: The coding scheme was developed as part of a prospective, longitudinal study examining the associations between maternal responsive behaviours and child language outcomes in slow-to-talk toddlers. In the first phase of the study, three coding systems were tested by coding five sample parent-toddler interactions and then comparing them based on a) the ease of method and thus likely intra- and inter-rater reliability, and b) the number of data points. The second phase was to demonstrate how the chosen method could be used in practice with a large at-risk group of toddlers.
\end{abstract}


Results: Of the three coding systems explored, the Observer® XT software was selected for ease of use and because detailed coding of free-play videos could be achieved in close to realtime. Intra- and inter-rater reliability were established in 251 mother-child free play videos, producing high intra-class correlation coefficients of 0.95 to 0.99 for the six behaviours. Conclusion: The study provides evidence that numerous parent-child interactions can be rigorously yet efficiently coded without substantial information loss. The observational mechanism in the current study has been fully developed and is shown to be feasible for research purposes focusing on parent-toddler interactions. However, further testing of the observational mechanism is required to examine whether the same results could be produced if coding was conducted 'live' and for shorter duration thereby making it readily useable for clinicians.

\section{Key Messages}

- Direct observational techniques are an important method for elucidating the behaviours and styles within parent-child interactions that may influence child language outcomes.

- The coding mechanism developed in the current study has the potential to be used in intervention studies to evaluate parenting programs aimed at improving child outcomes via the promotion of specific responsive parenting styles. 
- Given the growing interest in employing observational methods in child development research, the current paper should guide and inform future efforts to measure parentchild interaction not only within clinical samples, but at the community level.

\section{INTRODUCTION}

Parent-child interaction has been identified as playing a crucial role in child health and well-being. There is growing support for the beneficial impact that specific parent-child interactions can have on child development, in particular language development (TamisLeMonda \& Bornstein 2002; Snow 1977; Bornstein \& Tamis-LeMonda 1989).

Direct observational techniques are an invaluable method for elucidating the specific parent behaviours and styles within parent-child interactions that may enhance child developmental outcomes (Aspland \& Gardner, 2003; Wysoki, 2015). Numerous studies have confirmed a relationship between specific parenting styles/behaviours and child language outcomes in children with language disorder (Lasky \& Klopp, 1982), autism spectrum 
disorder (Perryman et al. 2013; Haebig et al. 2013) and developmental delay (Brady et al. 2004) as well as in typically developing samples (Tamis-LeMonda et al. 2001).

Not only can observational coding systems be an advantageous method for hypothesis testing relationships between parent behaviours and child language outcomes, but the coded behaviours may also provide outcome measures for interventions aimed at modifying such behaviours (Aspland \& Gardner, 2003; Bennetts et al. 2016). However, methodological challenges have limited the extent to which the associations between parenting and child language outcomes can be generalised beyond the study samples. While studies have conducted direct observations of parent-child interactions in order to measure some specific responsive behaviours, the intensive nature of coding observations has often meant very small numbers of participants (samples ranging from 5 to 40) in studies to date (TamisLeMonda et al. 2001; Girolametto et al. 1999; Lasky \& Klopp, 1982; Masur et al. 2005). There has also been a lack of any standard method for coding responsive behaviours, which precludes not only replication but also clear summations regarding the extent to which specific maternal behaviours of interest contribute to child language development.

While observational measures of parent-child interaction can be both complex and time-intensive, it provides an invaluable approach to addressing highly relevant research questions that may be more reflective of the behaviours of interest, compared to alternative methods such as self-report (Chorney et al. 2015). To the best of our knowledge, there was no appropriate coding system available for coding maternal responsive behaviours in a large community-based sample of mother-toddler dyads. Therefore, the purpose of this study was to demonstrate the development and implementation of a replicable, low-burden mechanism 
for observing, recording and analysing maternal responsive behaviours in a community-based cohort of 25124 -month-old slow-to-talk toddlers. Specifically, the study aimed to:

a) compare observational coding methods in order to establish the most time efficient and effective method, and

b) demonstrate how it could be used in practice with a large at-risk group of toddlers.

\section{METHOD}

\section{Study design and participants}

The coding mechanism was designed as part of a prospective longitudinal study examining the associations between maternal responsive behaviours and child language outcomes in slow-to-talk toddlers.

The first phase of this study was to establish an appropriate method for recording and coding maternal behaviours within parent-child interactions appropriate to large-scale population studies; this was previously lacking, and a major impediment to extending such techniques to representative, community-based samples. To achieve this first phase, colleagues and friends with toddlers of the same age as the study sample (i.e., around 24 months of age) volunteered to be videotaped playing with their child for 15 minutes $(n=5)$. They were told that the videos would then be used by the first author and a research assistant to practise coding parent-child interactions. The five free-play videos were recorded and then coded by the first author using three different methods. The strengths and limitations of each coding method were recorded. 


\section{Procedures}

The five volunteering mother-child dyads were video recorded during a free-play session in their homes by the first author. Before recording the mother-child interactions, mothers were instructed that they would be videotaped for 15 minutes during free-play with their child, using one of two standardised sets of toys (i.e., a farm or nurturing set) provided by the first author.

The first author set up the toys and video camera in a neutral area (e.g., living room), free of the child's own toys to avoid any distractions. The two bags of toys were put in separate spots on the floor. One designated toy from each bag was placed beside the bag (e.g. the baby doll from the nurturing set), with the other toys left in the bags to encourage the child to explore the contents of the bag. The first author started recording immediately after placing the bags of toys in position. Mothers were instructed to play as they normally would, with first author stating:

Now I will videotape you and your child during free-play for 15 minutes. The purpose of the video is to observe how your child communicates with a familiar person. I have set up a nurturing activity with a doll and related toys and a farm activity with a barn and animals. Your child may go to whichever activity he or she is interested in and may switch from one activity to another at any time. Please play with your child as you normally would. If your child stops playing or protests, I will stop the camera.

If the child fetched their own toys and was not interested in the toys provided, the mother was instructed to go along with what the child was interested in. Mother-child 
interactions were recorded using Hitachi DZ-GX5060SW DVD Camcorders and recorded onto Sony DVD DS DVD-RW discs.

\section{Coding scheme: maternal responsive behaviours}

The selected responsive behaviours were coded using continuous recording (i.e., each occurrence of a particular behaviour is recorded at the time of occurrence). Recording every occurrence of the target behaviours can be demanding on the coder if a large number of behaviours are to be targeted, resulting in high effort for low reliability (Martin \& Bateson, 2007). Therefore, the decision was made to restrict the coding to a maximum of six maternal behaviours highlighted in the literature to be of most importance to language acquisition. Six verbal responsive behaviours (expansions, imitations, interpretations, labels, responsive questions and supportive directives) were selected based on evidence and the quality of the supporting studies (see Appendix A).

\section{Comparing coding methods}

To address the first phase of the study and determine the most efficient and effective coding method, we explored three different coding systems. The first method considered was transcription using Transana software (Woods \& Fassnacht, 2007). Transana allows video files to be uploaded to the program after which transcripts can be created that correspond to those files. In Transana time codes may be inserted which link positions in the transcript with corresponding positions in the media file. The section of footage being watched is highlighted 
in the transcript; thus a section of video footage can be reviewed easily. Coding in Transana is done by creating keywords and applying them to the clip.

The second method examined was time sampling, which involves pre-determining intervals over the duration of a video clip and then assigning a behaviour to each segment (Oldfield, 2001). When trialling this method, 6 second intervals were chosen as this was deemed adequate for capturing the maternal behaviours, as the behaviours are quite short in duration. Therefore, a mother could obtain a maximum of 100 behaviours over a 10 minute clip. Behaviours may be recorded in a table either via pen and paper or electronically into a spreadsheet (the method used for this study). A major benefit to time sampling is that transcription is not necessary and therefore, with practice, video clips can be coded virtually in real-time. Thus, once familiar with the coding scheme, it is possible for a 10 minute video to take on average 10 minutes to code. Another benefit to time sampling is that it can be more reliable than continuous recording (i.e., coding every occurrence of a specific behaviour) as it is simpler and less demanding (Martin \& Bateson, 2007).

The final coding method trialled was to utilise a coding software program called the Observer $^{\circledR}$ XT (Noldus Information Technology, 2008). The Observer ${ }^{\circledR}$ XT is a software package designed for the collection, analysis and presentation of observational data. The Observer ${ }^{\circledR}$ XT allows the user to set up a coding scheme, whereby the user can define subjects, behaviours and modifiers. The video clip can then be viewed and scored in real-time by using mouse clicks or, alternatively, keystrokes that the Observer ${ }^{\circledR}$ XT assigns when the user creates a coding scheme. Scored events are automatically put into an event log. The method of continuous recording can consequently be used, whereby each occurrence of a 
behaviour and the time that it occurred is recorded, therefore preserving more information about specific behaviours than time sampling (Martin \& Bateson, 2007). The results calculated by the Observer ${ }^{\circledR} \mathrm{XT}$ are the total number of occurrences of each behaviour (frequency), the total duration of the clip and the rate per minute for each behaviour (mean number of occurrences per minute, which is calculated by dividing the total number of occurrences by the total duration of clip). These results are then displayed in a spreadsheet that can be exported to Excel. As with time sampling, the Observer ${ }^{\circledR}$ XT is very time efficient because, once a coder has practised using it, it provides the ability to code behaviours in realtime - in other words, a 10 minute clip takes approximately 10 minutes to code.

\section{RESULTS}

The time taken to transcribe a 10 minute video clip using Transana was approximately one hour and 45 minutes. It took another 15 minutes to insert the time codes and another hour to code the maternal behaviours (labels, imitations, interpretations, expansions, supportive directives and responsive questions). The total time taken to transcribe and code one 10 minute clip was approximately 3 hours. Thus, this method was excluded as the length of time was not deemed manageable for a large population-derived sample.

The latter two coding techniques (time sampling and the Observer ${ }^{\circledR}$ XT) were deemed to be the most appropriate techniques for this study. The five free-play videos of the group of self-volunteered dyads were coded by the first author using these two methods. Table 1 shows results from paired t-tests comparing the average frequency of each maternal 
responsive behaviour coded from 10 minutes of each of the five videos using the Observer ${ }^{\circledR}$ XT software compared to the time sampling method. The average frequency of imitations and expansions coded when using Observer ${ }^{\circledR}$ XT compared to time sampling for the five example videos was similar (mean difference: $0.2 ; 95 \% \mathrm{CI}$ : -0.4 to $0.8, \mathrm{p}=0.2$ for both behaviours). The mean difference between Observer and time sampling for supportive directives was $1.4(-1.0$ to 3.8$)$, this difference was not significant ( $\mathrm{p}=0.09)$. However, the average frequency of behaviours when coding with Observer ${ }^{\circledR}$ XT compared to time sampling was higher for labels (mean d: 4; 95\% CI: -1.2 to 9.2, $\mathrm{p}=0.05$ ), responsive questions (mean d: $3 ; 95 \% \mathrm{CI}-1.0$ to $7.0, \mathrm{p}=0.05$ ), and interpretations (mean d: $1.4 ; 95 \%$ CI: -0.3 to $3.1, \mathrm{p}=.04)$.

The Observer ${ }^{\circledR}$ XT was deemed the most appropriate method for coding a large sample of mother-child dyads because: a) behaviours can be coded in real-time; b) coding is continuous, preserving more information about specific behaviours than if using time sampling; and c) set up for coding is user friendly and time efficient.

\section{Testing the Observer ${ }^{\circledR}$ XT in a sample of slow-to-talk toddlers}

After establishing the most suitable coding method, the Observer ${ }^{\circledR}$ XT was then used to code maternal responsive behaviours in a sample of 251 slow-to-talk toddlers and their mothers who were recruited to the Let's Learn Language (LLL) randomized controlled 
trial (Wake et al., 2011). The sampling strategy and participant details have been described in detail elsewhere (Wake et al., 2011); briefly, mother-child dyads were recruited via a population-based language survey conducted in three local government areas in Melbourne, Australia, selected to span the full socioeconomic range from disadvantaged to advantaged. Parents provided written informed consent to take part. The study was approved by the Royal Children's Hospital Ethics in Human Research Committee (HREC 26028) and the University of Melbourne Research Office (ID\#: 0829736).

Of the 1,451 children eligible for recruitment, 1,138 (78.4\%) parents completed the screening language survey (100-word expressive vocabulary checklist) at child age 18 months. Children scoring below or at the $20^{\text {th }}$ percentile on the language survey were eligible for inclusion $(n=301)$. As most primary caregivers were mothers, free-play videos were excluded from the current study if the caregiver was not the mother. Free-play videos were also excluded if a language other than English was spoken during the recorded free-play. Therefore, the current study sample comprised 251 (83.4\%) of the 301 toddlers eligible to take part.

Among the participating slow-to-talk toddlers, almost half were girls $(48.6 \% ; 121 / 251)$ and just over a third were first born $(38.3 \%$; 96/251). The average age of toddlers during collection of the parent-child interaction data was 24.6 (SD 1.2) months. The proportion of children exposed to a non-English language for more than 10 hours per week was $11.2 \%$ (28/251). Because all children were slow-to-talk at age 18 months, the average standard scores for Expressive and Receptive Language on the Preschool Language Scale, $4^{\text {th }}$ edition (Zimmerman et al. 2002) at 24 months of age were two thirds of a standard deviation lower 
than the norming population (expressive language: 90.5 (SD 112.0); receptive language 88.9 (SD 14.4)).

Data collection occurred during the 24 month follow-up visits, which were conducted in the home by trained research assistants. The research assistant conducted a language assessment with the child, and the mother and child were also video recorded during 15 minutes of free-play, using the procedures described above for the example parent-child interaction videos.

\section{Reliability using Observer ${ }^{\circledR} \mathrm{XT}$ in the slow-to-talk toddler sample}

The primary rater (i.e., the first author) trained a secondary rater in the coding methods and use of Observer ${ }^{\circledR}$ XT. The secondary rater was a speech pathologist. The aim was to achieve training reliability above $80 \%$ agreement for each behaviour using videotape samples that were not part of the current study. Although there is no agreed cut off for an acceptable level of agreement, 70\% has commonly been considered acceptable (Aspland \& Gardner, 2003). Thus, in order to ensure excellent reliability, $80 \%$ was chosen as the cut off.

During this phase, the coding scheme was refined and examples were added to help clarify the definitions, resulting in the formulation of the coding manual (see Appendix A). Training occurred on a total of 11 videotapes. On the final three videotapes, the following percentage agreement for each behaviour was achieved: imitations $96.0 \%$; expansions $84.9 \%$; interpretations $84.2 \%$; labels $88.5 \%$; supportive directives $84.6 \%$; and responsive questions 
$90.1 \%$. These figures indicated that the coding system and coders were reliable and that interrater reliability was ready to be completed.

Both intra-rater and inter-rater reliability were calculated using the intra-class correlation coefficient, which is appropriate for continuous data (Aspland \& Gardner, 2003). The intra-class correlation will be lower when there is a low correlation between coders or when there are large mean differences between coders (Stemler \& Tsai, 2008).

Intra-rater Reliability. All 251 videos were coded by the first author (primary coder). In order to check consistency over the duration of coding, a random $10 \%$ of child IDs was generated by the primary coder using Stata 11.0 (Statacorp LP, 2009) for the coded motherchild dyads at the beginning, middle and end of the coding period. Intra-rater reliability for the current study was high, with the following achieved for each behaviour: imitations .99 ; expansions .99; interpretations .96; labels .98; supportive directives .97; responsive questions .99 .

Inter-rater Reliability. A secondary rater coded $10 \%$ of randomly selected videos from the study sample $(\mathrm{N}=25)$. The secondary rater re-coded the videos at the beginning, middle and end of the coding period. At no time did the secondary rater have access to the codes of the primary rater. Intra-class correlation coefficients were extremely high for inter-rater reliability across all six behaviours: imitations .97 ; expansions .99 ; interpretations .96; labels.96; supportive directives .97; and responsive questions .95 . 


\section{DISCUSSION}

This paper reports on the successful development of an explicit, replicable and highly reliable mechanism for coding and reporting maternal responsive behaviours. Furthermore this methodology is feasible for use in the population setting. One of the major disadvantages to conducting direct observation of parent-child interaction is that the procedures involved are often time consuming and costly (Gardner, 2000). The current study demonstrates that it is possible to observe, code and analyse maternal responsive behaviours in a large sample of mother-child dyads. The Observer® XT was deemed the most appropriate method for coding a large sample of mother-child dyads because: a) behaviours can be coded in real-time; b) coding is continuous, preserving more information about specific behaviours than if using time sampling; and c) set up for coding is user friendly and time efficient.

In addition to the strengths of the current study, there are a number of limitations. Despite the value of the coding method used in this study, there is a substantial cost involved in the initial purchase of the coding software, which may deter some from using it. However, the likely cost savings over the duration of the coding period due to the minimal time required to set up, code and analyse the data are likely to far outweigh the initial cost.

The coding scheme was developed with English speaking mother-toddler dyads. Therefore, findings may not fully generalise to non-English speaking families. There is evidence to show that parent-child interactions and maternal responsive behaviours may differ dependent on family cultural background (Best et al. 1994; Richman et al. 1992; Bornstein et al. 1992). In addition, the coding scheme is tailored for use with 2 year olds, 
however, it could be readily adapted to measure maternal behaviours thought to be more appropriate for use with a) different languages and b) other age groups.

Observational measures of parenting styles and behaviours could provide health professionals with better tools to identify those toddlers who may benefit from programs promoting beneficial parent-child interaction. The observational mechanism in the current study is fully developed and feasible for research purposes focusing on parent-toddler interactions. This type of observational system could be used to evaluate parenting programs aimed at improving child outcomes via the promotion of specific responsive parenting styles. Further testing the mechanism to see if the same results could be produced when coding is done 'live' and over a shorter duration of observation, such as 5 minutes, could make it useable for clinicians.

The high levels of reliability and explicit development and operationalisation of the coding scheme ensure this observational mechanism is suitable as a direct measure of responsive maternal behaviours. In future research, this mechanism could be used to measure associations between maternal responsive behaviours and language outcomes in different populations of children, such as those children growing up in socially disadvantaged areas. This may be particularly important given the substantial evidence suggesting that the quality and quantity of parent-child interaction mediates the association between socio-economic status and language development (Hart \& Risley, 1995; Rowe, 2008). The coding mechanism also has the potential to be used in intervention studies to evaluate parenting programs aimed at improving child outcomes via the promotion of specific responsive parenting styles. The rigorous methodology and highly reliable coding of maternal responsive behaviours in this 
study takes observational techniques from the realm of small clinical studies to large community-based studies in the field of child language development.

\section{References}

Ainsworth, M. D. S., \& Bell, S. M. (1970). Attachment, exploration, and separation:

Illustrated by the behavior of one-year-olds in a strange situation. Child development, 49-67.

Aspland, H. \& Gardner, F. (2003) Observational Measures of Parent-Child Interaction: An Introductory Review. Child and Adolescent Mental Health, 8, 136-143.

Australian Bureau of Statistics (2006) Socio-Economic Indexes for Areas. Australian Bureau of Statistics, Canberra, Australia.

Bennetts, S. K., Mensah, F. K., Westrupp, E. M., Hackworth, N. J., \& Reilly, S. (2016) The agreement between parent-reported and directly measured child language and parenting behaviours. Frontiers in Psychology, 7, 1-18.

Best, D. L., House, A. S., Barnard, A. E. \& Spicker, B. S. (1994) Parent-Child Interactions in France, Germany, and Italy: The Effects of Gender and Culture. Journal of Crosscultural Psychology, 25, 181-193.

Bornstein M. H. \& Tamis-LeMonda C. S. (1989) Maternal responsiveness and cognitive development in children. New Directions for Child and Adolescent Development, 43, 49-61.

This article is protected by copyright. All rights reserved. 
Bornstein, M. H., Tamis-LeMonda, C. S., Hahn, C. S. \& Haynes, O. M. (2008) Maternal responsiveness to young children at three ages: Longitudinal analysis of a multidimensional, modular, and specific parenting construct. Developmental Psychology, 44, 867-874.

Bornstein, M. H., Tamis-LeMonda, C. S., Tal, J., Ludemann, P., Toda, S., Rahn, C. W., Pêcheux, M., Azuma, H. \& Vardi, D. (1992) Maternal responsiveness to infants in three societies: The United States, France, and Japan. Child Development, 63, 808-821.

Brady, N. C., Marquis, J., Fleming, K. \& McLean, L. (2004) Prelinguistic predictors of language growth in children with developmental disabilities. Journal of Speech, Language, and Hearing Research, 47, 663-677.

Chorney, J. M., McMurtry, C. M., Chambers, C. T., \& Bakeman, R. (2015). Developing and modifying behavioral coding schemes in pediatric psychology: a practical guide. Journal of pediatric psychology, 40(1), 154-164.

Eshel, N., Daelmans, B., de Mello, M. C. \& Martines, J. (2006) Responsive parenting: Interventions and outcomes. Bulletin of the World Health Organization, 84, 991-998.

Gardner, F. (2000) Methodological issues in the direct observation of parent-child interaction: Do observational findings reflect the natural behavior of participants? Clinical Child and Family Psychology Review, 3, 185-198.

Girolametto, L., Weitzman, E., Wiigs, M. \& Pearce, P. S. (1999) The relationship between maternal language measures and language development in toddlers with expressive vocabulary delays. American Journal of Speech-Language Pathology, 8, 364-374.

This article is protected by copyright. All rights reserved. 
Girolametto, L., Bonifacio, S., Visini, C., Weitzman, E., Zocconi, E. \& Pearce, P. S. (2002) Mother-child interactions in Canada and Italy: Linguistic responsiveness to late-talking toddlers. International Journal of Language \& Communication Disorders, 37, 153-171.

Haebig, E., McDuffie, A., Weismer, S. E., Hammer, C. S. \& Brady, N. (2013) The contribution of two categories of parent verbal responsiveness to later language for toddlers and preschoolers on the autism spectrum. American Journal of SpeechLanguage Pathology, 22, 57-70.

Hart, B. \& Risley, T. R. (1992) American parenting of language-learning children: Persisting differences in family-child interactions observed in natural home environments. Developmental Psychology, 28, 1096-1105.

Hart B. \& Risley, T. (1995) Meaningful Differences in the Everyday Experience of Young American Children. Paul H Brookes Publishing, Baltimore, MD, US.

Hebert, H., Swank, P., Smith, K. \& Landry, S. (2004) Maternal support for play and language across early childhood. Early Education and Development, 15, 93-116.

Landry, S. H., Smith, K. E., Swank, P. R., Assel, M. A. \& Vellet, S. (2001) Does early responsive parenting have a special importance for children's development or is consistency across early childhood necessary? Developmental Psychology, 37, 387-403.

Lasky, E. Z. \& Klopp, K. (1982) Parent-child interactions in normal and language-disordered children, Journal of Speech and Hearing Disorders, 47, 7-18.

Martin, P. \& Bateson, P. (2007) Measuring Behaviour: An Introductory Guide. $3^{\text {rd }}$ edition (Cambridge, UK: Cambridge University Press).

This article is protected by copyright. All rights reserved. 
Masur, E., Flynn, V. \& Eichorst, D. L. (2005) Maternal responsive and directive behaviours and utterances as predictors of children's lexical development. Journal of Child Language, 32, 63-91.

McFadden, K. E. \& Tamis-Lemonda, C. S. (2013) Maternal responsiveness, intrusiveness, and negativity during play with infants: Contextual associations and infant cognitive status in a low-income sample. Infant Mental Health Journal, 34, 80-92.

Noldus Information Technology (2008) The Observer ${ }^{\circledR}$ XT, Version 8.0. Noldus Information Technology b.v., Wageningen, The Netherlands.

Oldfield, S. (2001) A critical review of the use of time sampling in observational research. Nursing Times Research, 6, 597-608.

Perryman, T. Y., Carter, A. S., Messinger, D. S., Stone, W. L., Ivanescu, A. E. \& Yoder, P. J. (2013) Brief report: parental child-directed speech as a predictor of receptive language in children with autism symptomatology. Journal of Autism and Developmental Disorders, 43, 1983-1987.

Richman, A. L., Miller, P. M. \& LeVine, R. A. (1992) Cultural and educational variations in maternal responsiveness. Developmental Psychology, 28, 614-621.

Rowe, M. L. (2008) Child-directed speech: Relation to socioeconomic status, knowledge of child development and child vocabulary skill. Journal of Child Language, 35, 185-205.

Smith, K. E., Landry, S. H. \& Swank, P. R. (2006) The role of early maternal responsiveness in supporting school-aged cognitive development for children who vary in birth status. Pediatrics, 117, 1608-1617.

This article is protected by copyright. All rights reserved. 
Snow, C. E. (1977) Mother's speech research: From input to interaction. In: Talking to Children: Language Input and Acquisition (eds. C. E. Snow \& C. A. Ferguson), pp. 3149. Cambridge University Press: Cambridge.

Statacorp LP. (2009) Stata: Release 11. StataCorp LP, College Station, TX.

Steelman, L. M., Assel, M. A., Swank, P. R., Smith, K. E. \& Landry, S. H. (2002) Early maternal warm responsiveness as a predictor of child social skills: Direct and indirect paths of influence over time. Journal of Applied Developmental Psychology, 23, 135156.

Stemler, S. E. \& Tsai, J. (2008) Best practices in Inter-rater Reliability: Three Common Approaches. In: Best Practices in Quantitative Methods (ed. J. Osbourne), pp. 29-49. Thousand Oaks, CA: Sage Publications Inc.

Tamis-LeMonda C. S., Bornstein, M. H.\& Baumwell, L. (2001) Maternal responsiveness and children's achievement of language milestones. Child Development, 72, 748-67.

Tamis-LeMonda, C. S. \& Bornstein, M. H. (2002) Maternal responsiveness and early language acquisition. Advances in Child Development and Behavior, 29, 90-129.

Tamis-LeMonda, C.S., Bornstein, M.H. \& Damast, A. M. (1996) Responsive parenting in the second year: Specific influences on children's language and play. Early Development and Parenting, 5, 173-183.

Tomasello, M., \& Todd, J. (1983) Joint attention and lexical acquisition style. First Language, 4(12), 197-211.

Tomasello, M. \& Farrar, M. J. (1986) Joint attention and early language. Child Development, 57, 1454-1463.

This article is protected by copyright. All rights reserved. 
Wong, T. P., Moran, C. \& Foster-Cohen, S. (2012) The effects of expansions, questions and cloze procedures on children's conversational skills. Clinical Linguistics \& Phonetics, 26, 273-287.

Woods, D. \& Fassnacht, C. (2007) Transana v2.2x. Madison, WI: The Board of Regents of the University of Wisconsin System.

Wysocki, T. (2015) Introduction to the Special Issue: Direct Observation in Pediatric

Psychology Research. Journal of Pediatric Psychology, 40(1), 1-7.

Yoder, P. J., Warren, S. F., McCathren, R. \& Leew, S. V. (1998) Does adult responsivity to child behaviour facilitate communication development? In: Transitions in Prelinguistic Communication: Volume 7 of Communication and language intervention series (eds. A. M. Wetherby, S. F. Warren and J. Reichle), pp.39-58. Baltimore: Paul H. Brookes.

Zimmerman, I. L., Steiner, V. G. \& Pond, R. E. (2002) Preschool Language Scale, $4^{\text {th }}$ edition. Harcourt Assessment Inc, San Antonio, TX. 
Table 1 Frequency of responsive behaviours coded using Observer vs time sampling

\begin{tabular}{|c|c|c|c|c|c|}
\hline \multirow[b]{2}{*}{$\begin{array}{c}\text { Maternal behaviours } \\
\text { (frequency) }\end{array}$} & \multicolumn{2}{|c|}{ Mean (SD) } & \multirow[b]{2}{*}{ Mean difference } & \multirow[b]{2}{*}{$95 \% \mathrm{CI}$} & \multirow[b]{2}{*}{$p^{*}$} \\
\hline & $\begin{array}{c}\text { Observer } \\
\qquad(\mathbf{n}=5)\end{array}$ & $\begin{array}{c}\text { Time Sampling } \\
\qquad(n=5)\end{array}$ & & & \\
\hline Expansions & $9.8(7.6)$ & $9.6(7.4)$ & 0.2 & $(-0.4$ to 0.8$)$ & 0.2 \\
\hline Imitations & $3.6(3.0)$ & $3.4(3.2)$ & 0.2 & $(-0.4$ to 0.8$)$ & 0.2 \\
\hline Interpretations & $10(4.3)$ & $8.6(3.2)$ & 1.4 & $(-0.3$ to 3.1$)$ & 0.04 \\
\hline Labels & $15.5(5.0)$ & $11.4(4.7)$ & 4 & $(-1.2$ to 9.2$)$ & 0.05 \\
\hline Supportive Directives & $5.8(2.4)$ & $4.4(1.7)$ & 1.4 & $(-1.0$ to 3.8$)$ & 0.09 \\
\hline Responsive Questions & $15.8(7.6)$ & $12.8(5.6)$ & 3 & $(-1.0$ to 7.0$)$ & 0.05 \\
\hline
\end{tabular}

CI, Confidence Interval; SD, Standard Deviation.

*One-tailed p-value presented as Observer values will always be equal to or greater than time sampling value.

This article is protected by copyright. All rights reserved. 


\section{Appendix A: Coding manual for maternal responsive behaviours}

The six maternal responsive behaviours are mutually exclusive, meaning that only one code may be assigned to a maternal utterance. In some cases, mothers used several utterances in a row. To address this situation, a hierarchy of codes was incorporated into the coding scheme, so that it was clear to the coder which utterance should be coded. For example, in a series of maternal utterances whereby a mother utters a string of sentences without any definite pauses, it was decided that only the first utterance would be coded and the rest would be ignored.

Segmentation was based on a grammatical unit + breath unit + terminal intonation contour (i.e., the end of a pattern of pitch in speech). This hierarchy of codes was established as it was far too difficult for a coder to retain all of the information from a series of utterances, which could lead to confusion of which behaviours to code and this in turn would weaken reliability. An example of the hierarchy as it would be applied to a string of maternal utterances is as follows:

E.g. C:Drink. M:Drink.[Imitation] Let's give baby a drink. [Expansion] What is baby going to drink? [Question].

This would be coded as imitation (as this is the first utterance).

\section{$\underline{\text { Expansions }}$}

Expansions are coded when a mother repeats one or all of the child's preceding words and adds to the child's preceding verbalisation (Girolametto et al. 1999, Girolametto et al. 2002, Lasky and Klopp 1982). This includes both simple and complex expansions. 
A simple expansion is when a mother repeats immediately the child's preceding word approximation or verbalisation and completes the utterance by adding one or more morphemes (i.e. smallest meaningful unit of language, which may be a word or word element) or words.

\section{E.g. C:Ball. M:It's a red ball.}

If a mother repeats the child's preceding vocalisation/verbalisation and adds a question within the same utterance, this is coded as expansion (complex expansions), not both imitation and question. In the following example, the mother repeats the child's preceding word (dirt) "Dirt" and "what's growing in the dirt" (i.e., this is one utterance).

E.g. C:Dirt. M:Dirt, what's growing in the dirt?

\section{$\underline{\text { Imitations }}$}

An imitation is coded when a mother repeats the child's preceding vocalisation or verbalisation exactly or with a reduction of words (Girolametto et al. 1999, Girolametto et al. 2002, Lasky and Klopp 1982). Imitations must be exact.

E.g. C:Bottle. M:Bottle.

C:Mummy let's go. M:Let's go.

\section{$\underline{\text { Interpretations }}$}

This article is protected by copyright. All rights reserved. 
An interpretation is coded when a mother responds to the child's vocalisation or verbalisation with one or several words to interpret the child's intended message using the context as a cue. (Girolametto et al. 1999, Girolametto et al. 2002). This includes all interpretations of vocalisations as words and all interpretations of word approximations as words.

E.g. C: Vocalises while playing with doll. M:A bottle for the baby.

C:Bi fir ti. M:She's a bit thirsty.

\section{$\underline{\text { Labels }}$}

A label is coded when a mother labels an object or action, which is the focus of the child, with the label in the final position of the carrier phrase (Girolametto et al. 1999, Girolametto et al. 2002, Tomasello and Farrar 1986).

E.g. C:Playing with a toyhorse. M:That's a horse.

C: Child is playing with a toy stove, turning knobs. M:You're cooking.

\section{$\underline{\text { Supportive Directives }}$}

A supportive directive is coded when a mother directs the child or commands the child to verbalise or do an action in relation to what the child is focused on (Masur et al. 2005).

E.g. C: Playing with doll. M: Feed the doll.

C: Playing with doll. M:Dress the baby. 


\section{$\underline{\text { Responsive Questions }}$}

A responsive question is coded when the mother asks a 'wh' question (including 'what', 'when', 'why', 'how', 'who' and choice questions) that is immediate and dependent on the child's preceding act (Tamis-LeMonda et al. 2001). The mother then waits (even briefly) for a response. The question can be about an object, event or activity. Yes/no questions are not coded.

E.g. C: Child is holding a horse. M:What's that?

C: Child is playing with a toy train. M: What does the train say? 


\section{University Library}

\section{- M M N E R VA A gateway to Melbourne's research publications}

Minerva Access is the Institutional Repository of The University of Melbourne

Author/s:

Levickis, P;Reilly, S;Girolametto, L;Ukoumunne, OC;Wake, M

Title:

A replicable, low-burden mechanism for observing, recording, and analysing mother-child interaction in population research

Date:

2018-11-01

Citation:

Levickis, P., Reilly, S., Girolametto, L., Ukoumunne, O. C. \& Wake, M. (2018). A replicable, low-burden mechanism for observing, recording, and analysing mother-child interaction in population research. CHILD CARE HEALTH AND DEVELOPMENT, 44 (6), pp.901-907. https://doi.org/10.1111/cch.12615.

Persistent Link:

http://hdl.handle.net/11343/284370 